\title{
HOSPITAL SERVICE PLANS: THEIR CONTRACT PROVISIONS AND ADMINISTRATIVE PROCEDURES
}

\author{
MAURICE J. NORBY*
}

Hospital service plans have developed a form of protection which, when reduced to its simplest terms, means the application of the principle of collective cooperation to the equalization of losses resulting from the uncertainty of continued good health. It cannot be considered health insurance, inasmuch as it provides for the contingency of only one form of health service, namely, hospitalization. The fact that hospital service plans have enjoyed wide acceptance during their short lives has probably resulted from a realization that, wherever there is a contingency, the easiest and securest way of providing against it is by uniting with others so that each person may subject himself to a small deprivation in order that no individual may be subjected to a great immediate expense.

The American Hospital Association endorsed the principle of prepayment plans for hospital care in February, I933. At that time, the Association established the following set of principles which it felt should characterize such plans: (I) emphasis on public welfare; (2) limitation to the provision of hospital service; (3) enlistment of professional and public interest; (4) free choice of physician and hospital; (5) non-profit organization; (6) economic soundness; and (7) dignified promotion and administration. These principles later formed the basis of an approval program which is administered by the Commission on Hospital Service of the American Hospital Association.

\section{The Corporation}

The operation of a hospital service plan is effected through a corporation which is established in conformity with local legislation. The corporation usually is organized as an agency which undertakes to establish, maintain, and operate a plan whereby hospitalization may be provided to subscribers in any hospital with which the corporation may contract for such service. In several communities, the plan corporation is actually an organization of hospitals which appoints the service association as its agent to operate the plan under its supervision and direction. Under this type of organization, the subscribers to the plan have no right, claim or cause of action either

- B.A., r930, St. Olaf College; M.A., r934, University of Minnesota. Research Director, Council on Hospital Service Plans of the American Hospital Association; former executive director, Hospital Service Association of Pittsburgh. 
at law or in equity against the service association, but must make complaints directly against member hospitals. In actual operations, the net result of either type of organization is the same. In the first instance, the subscribing public contracts with the hospital service corporation, which is an agency not producing or having control of hospital service but which contracts with hospitals to provide the specified benefits. In the second instance, the public actually contracts with the source of the hospital service which will be provided to them in accordance with contractual agreements.

Eligibility for membership in hospital service plan corporations does not take a definite pattern. In several communities any person interested in the promotion of proper health service is eligible for membership in the corporation. Such individuals may be elected to office without regard to their actual association with hospitals or other health agencies. Other corporations specify that membership in the corporation must be equally divided between the interests of hospitals, the medical profession, and the public. Several hospital service plan corporations limit membership to representatives of hospitals only. In these corporations membership is usually divided between hospital administrators and hospital trustees.

The responsibilities of participating hospitals make it desirable that their interests be protected; therefore, a majority of the membership of the board of directors is usually representative of such hospitals. It has been found desirable so to constitute the governing bodies that the representatives of hospitals or medical profession or public may not pursue selfish interests to the detriment of the plan.

The by-laws of the corporation usually provide for a board of directors to administer the activities of the corporation. This board may be elected from the membership of the corporation, or may be designated as the total membership of the corporation. If specific representation of hospitals, medical societies, and public is required in the membership in the corporation, this same proportion of representation is usually designated for membership on the board of directors.

\section{Hospital Service Plan Administration}

The management of a hospital service plan is similar to that of proprietary businéss. An executive officer, who is responsible to the board of directors, is usually in direct administrative control of the organization. Theoretically he is in charge of all departments of the organization. In practice, however, as the plan grows in size, he usually centers his attention on the coordination of the various phases of the enterprise and appoints subordinate officers to direct activities in specialized departments. Unlike commercial insurance and private business, this executive officer is usually not a member of the board of directors. Although he is responsible for the success of the venture, his opinions, in a majority of the plans, are not democratically represented on the governing board.

The administrative organization of a hospital service plan usually includes the following departments: ( $\mathrm{r}$ ) the field service and acquisition department, the first duty of which is to secure new business for the corporation; (z) the contract or underwriting department, which examines statements of the applicant, issues sub- 
scriber contracts and establishes office records on each new account; (3) the hospital department, which receives all notifications of hospital admissions from member hospitals and accepts or rejects liability for such care; (4) the comptroller's department, which handles the accounting and financial records of the corporation; (5) the cashiering department, which receives all income to the corporation and maintains a current record of receipts; (6) the actuarial and statistical department, which prepares experience tables for use in analyzing the results of the corporation activities; (7) the tabulating department (in large organizations), which mechanically produces information from existing records and prepares reports upon order from various department heads; (8) the educational and publicity department, which maintains a proper relationship between the corporation and the public, and effects the promotional program; (9) the purchasing and supply department; (Io) the mailing department, and (xI) the personnel department, the functions of which are obvious, and which are usually instituted only in large organizations.

\section{Hospital Contracts}

The hospitals which desire to.participate in hospital service plans apply to become members and agree that, in consideration of the corporation's payment of a fixed amount of money per day for hospital services rendered to subscribers to the plan, they will render such services to subscribers and abide by the provisions of the subscriber's contract. The amounts of the per diem payments are subject at all times to the determination of the board of directors and the approval of the regulatory bodies in those states where regulation is specified by enabling legislation.

The hospital contract is usually a restatement of the subscriber contract, with the further provision that the contracting hospital shall be liable for the provision of hospital service regardless of the financial ability of the corporation to pay that hospital for services rendered. It has been established that some agency must be responsible for the fulfillment of the terms of the subscriber contract. Three ways of effecting such a guaranty are possible: an assessment feature in the subscriber contract; a surplus guaranty fund available for the purchase of hospital care; or a subscriber contract underwritten by a responsible agency.

Mutual and stock insurance companies use one or the other, or a combination of both, of the first two possibilities. Hospital service plans operate under legislation which does not require, and in some instances does not permit, the establishment of either of these two safeguards for subscribers. If hospital service plans occupy a unique position, it is because of their ability to offer a "service contract" by virtue of a financial guaranty by participating hospitals. This guaranty, therefore, must be assumed by the member hospitals through which the service specified in the subscriber contract is made available. Such a regulation is a public safeguard.

In certain plans, this financial responsibility extends not alone for the provision of hospital service to subscribers but also to the continued operation of the plan in paying current operating expenses. The following definition of hospital responsibility is a quotation from "The Standards for Non-Profit Hospital Service Plans" which 
have been established by the Commission on Hospital Service of the American Hospital Association.

"The hospital service benefits of a non-profit hospital service plan should be guaranteed by the member hospitals during the life of the subscriber's contract. The ultimate economic responsibility for service to subscribers enrolled within any given time should be assumed by the member hospitals through definite contractual agreement with the hospital service plan. All contracts involving the plan, the subscribers and the member hospitals should be equitable and consistent with respect to the rights and the obligations of each party."

The hospital contract is usually cancellable in a manner which provides the corporation an opportunity to terminate its obligation to subscribers. That is, if the subscriber contract is cancellable on a 30-day notice, usually the hospital contract is cancellable on 60 days' notice. If the subscriber contract must continue in effect until the end of the contract year, the hospital contract is cancellable on 13 months' notice. During this period, however, the obligation of the hospital continues in effect for all contract holders only until the termination of the subscription years of the contracts in effect on the date of notification of cancellation by the hospital.

In case of liquidation of the assets of the corporation, either the corporation continues to provide hospital service to its membership without collecting further dues from and after the date set for liquidation until all surplus accounts have been dissipated through the provision of hospital service or all surplus funds are divided pro rata among member hospitals in accordance with the amount of hospital service which has been provided during a specified period prior to the date of liquidation.

\section{The Subscriber Contract and its Duration}

The agreement with the subscriber is a contract whereby the corporation agrees to provide certain hospital services the need for which may arise from some contingent event. Inasmuch as the contract is not issued upon the strength of a medical examination, but rather in accordance with a statement by the applicant to the effect that he or she knows of no need for immediate hospital care on the date of application, the corporation is not obligated to provide such hospital service resulting from a false warranty. The contract is valid only if there is present the specific element of risk which the corporation assumes.

The contract specifies a provision of service and not a cash indemnity. It carries the name of the person or personis entitled to benefits in accordance with the terms and provisions enumerated and indicates the manner in which additional family members may be added to the contract, if they are covered by the plan. It defines the extent and duration of hospital service, the manner and amount of periodic subscription payments, conditions affecting the provision of hospital service, the manner in which the contract may be terminated, the effective date of membership, and other information affecting the relationship between the subscribers and the corporation. 
The benefits included in the contract are described in the succeeding section. In no instance do they include the services of a subscriber's attending physician, surgeon, special nurses or their board. The free choice of physician and hospital remains with the subscriber. Hospital services are rendered by the corporation only upon compliance with rules and regulations of the hospital selected for service.

Most contracts provide that if at the time the subscriber applies for hospital service, the member hospital selected for use is unable to furnish the required service, the subscriber, with the consent of his physician, is free to utilize the services of another member hospital. Usually the liability of the corporation is satisfied by refunding the amount of all subscriber's prepayments on such date as it is established that all member hospitals, because of overcrowded conditions or for other reasons, are unable to accept subscribers for service. In some instances, the plan provides the subscriber with a cash per diem payment during the period he is unable to receive hospital care in a hospital.

Usually benefits are limited to the contract year, defined as a 12-month period from and after the effective date of the contract. The benefits of the plan are not assignable and are personal to the subscriber. The hospital service plan corporations, with one exception, are not subrogated to the rights of subscribers who may also recover from any person or persons other than the corporation or any member hospital for service rendered under the contract.

The amount and manner of payment of the annual charges may or may not be stated in the subscriber contract. These charges are usually subject to revision from time to time by the directors of the corporation. In the event of a change, the subscribers must be notified. This change usually does not affect the amount of the annual charges under existing agreements, until the end of the contract year. Prior to that time, the subscriber is required to sign a new application setting forth the amount of the new charges. If the subscriber fails to execute such an application, bis contract, by contract provision, will automatically terminate at the end of his contract year.

All contracts issued by hospital service plans are cancellable, although the period of cancellation varies. Without exception, the contract may be cancelled on a monthly basis by the subscriber by reason of default in payment, by reason of request for cancellation, or by reason of subscriber's death. Some subscriber contracts provide for cancellation by the corporation on 30 days' 'notice; others provide for cancellation only upon the termination of the subscription year. Usually the agreement may be reinstated by the subscriber after it has been cancelled if he meets specific regulations established by the corporation. In certain plans the subscribers who request reinstatement of their contracts must pay reinstatement fees plus unpaid subscription dues accumulated during the period of delinquency; and in others the subscriber's reapplication is subject to a waiting period before benefits are available.

The printed contract constitutes the entire agreement between the corporation and 
the subscriber. No employee is authorized to change the terms of the contract or to make verbal exceptions to its contents.

\section{Scope of Benefits to Contract Holders}

Hospital benefits are usually provided for all types of illness and injuries which are regularly treated in member hospitals. In some plans, benefits aro available for all types of illnesses on and after the effective date of the contract. In others, waiting periods ranging from ten days to six months are effective for all elective hospitalization, with immediate benefits available only for accidental injuries and illnesses which in the opinion of the medical adviser were unpredictable and in the nature of an emergency. With the exception of one plan, the plans exclude from benefits all conditions known to the subscriber to exist and to require hospital care on the date of application. Out-patient or ambulatory care, excepting for cases of accidental injury, is not generally provided.

Usually such conditions as pulmonary tuberculosis (after diagnosis), venereal diseases, quarantinable diseases, and mental disorders are not acceptable illnesses for which the subscriber may claim benefits under the hospital service plan. These conditions are either long-term illnesses or the general hospital is not equipped to render service for them. They have been excluded from benefits on this basis. Hospitalization for which the subscriber is entitled to workmen's compensation benefits, has without exception been excluded from the benefits of plans on the ground that this contingency is provided for by law.

The nature of the hospital care described in the subscriber's contract is not the same in all plans. Hospital policies vary in various locations, and the definition of hospital care conforms to common practice under local conditions. In all communities bed and board and routine nursing service are considered a part of hospital care and, therefore, hospital service plans without exception provide these benefits. Usually a maximum of $2 \mathrm{I}$ days of hospital care may be used by the subscriber during any one contract year in one or more hospital admissions for one or more illnesses. Several plans have provided for 30 days of service and several extend the period of hospitalization year by year as an inducement to the subscriber to continue his membership. The majority of the plans to date have provided semi-private accommodations to contract holders. The term "semi-private accommodations" usually refers to a two- or a four-bed room. However, in some plans this classification may include any multiple bed accommodations in which the patient is free to choose his own medical adviser. Although the type of accommodations provided is defined as semiprivate, the subscriber patient has the privilege of using either less or more expensive accommodations. If private room accommodations are elected, then, upon the approval of the patient's attending physician, the subscriber is entitled to a cash allowance which is applied toward the purchase of the more expensive room. In certain instances, a subscriber patient's economic status may be such that without member- . ship in the plan, he would be considered medically indigent by the social service department of the hospital. In order that this patient may still have the privilege of 
free medical service, the member hospitals in these plans may upon his own request; provide him with ward accommodations and the privilege of using a house physician. If the subscribing patient uses ward accommodations in place of semiprivate service which is more expensive, he does not receive the credit of the cash difference between the cost of these two types of accommodations.

The special hospital services which are provided as benefits usually are the same regardless of what type of room accommodations the subscribing patient elects to use, although in one instance a straight cash credit is provided to that patient who elects to use private rather than semi-private accommodations, and in another instance certain limitations on amount of special service are placed on private room service for the subscriber patient.

Recently several communities have established ward service contracts which are sold at a lower cost than semi-private service contracts. However, the cost probably has not been reduced to a point where it will be attractive to the majority of the very low income workers. Hospital service plans have enrolled primarily the upper middle-income group. It is felt that if they wish to serve adequately the greatest need, they must extend their services to include people who are self-supporting but who are not in a position to provide either themselves or their families with what might be termed a "luxury" health service.

Usually the use of the operating room is specified as a contract benefit without regard to number of times its use becomes necessary. Likewise, in a majority of the plans anesthesia is provided if it is administered by a salaried employee of the hospital. The contract specifies the provision of ordinary dressings, drugs, and laboratory work. The indefiniteness of this description has led to considerable controversy and misunderstanding on the part of the subscribing public. Recent tendencies are to provide all surgical dressings, plaster casts, splints, etc., to provide only drugs which are listed in the pharmacopoeia, and to define "laboratory service" by specifying certain definite procedures.

Plans which provide physiotherapy and X-ray service about equal in number those which do not. In one plan, X-ray service is provided to an amount not to exceed $\$ 15.00$, and a $25 \%$ discount is allowed on all X-ray service beyond that maximum charge.

The benefits usually do not include admission of patients to member hospitals for laboratory or X-ray examinations solely for diagnostic purposes. This limitation of service has been difficult to administer, inasmuch as there is no definite division between diagnostic and therapeutic service. Some plans have determined that a patient shall be eligible for benefits regardless of the type of service which he receives in the hospital, if he remains in a hospital bed for 24 hours or more. Other plans have excluded all procedures used in conjunction with diagnostic services, even though they also may be prescribed for therapeutic service.

Although hospital service plans usually provide hospital service rather than cash reimbursement, in certain instances the service element of the contract is limited. 
One plan indemnifies subscribing patients against specialized hospital services and actually reimburses him in cash for expenses incurred in these departments of the hospital. In other communities, indemnifications for incidental professional services are handled as bookkeeping entries on the ledgers of the hospital service plan; but no actual cash payments to patients, hospitals, or doctors are made from these entries.

A majority of plans provide obstetrical care after the subscriber has been a member of the plan for a period varying from nine months in some plans to one year in others. The use of the delivery room, if obstetrical care is covered, care of newborn children and attendant service is provided as for a regular hospital illness. Certain difficulties of interpretation of the contract have arisen in a number of plans concerning the "waiting period" because the statement of what was included in maternity service was indefinite. In the past, most plans have excluded from maternity service all conditions resulting from pregnancy during the period of pregnancy and, in certain instances, all conditions resulting from childbirth, whether it was a result of a previous or a current pregnancy. A number of plans have interpreted miscarriages, ectopic pregnancies, etc., as accidental occurrences and, therefore, serviceable under the terms of the hospital service plan.

It is the ambition of hospital service plans to provide the patient with a receipted hospital bill when he leaves the institution. A contract providing such all-inclusive benefits would obyiously be acceptable to the subscribing public and equally advantageous from the point of view of the hospital, the medical profession, and the plan.

\section{Public Relations and Promotion}

The essence of success of hospital service plans is not salesmanship; rather, it is a program of sound public relations. Inasmuch as the means of obtaining publicity are manifold, the questions of policy and acceptability of the plan in the community are of prime importance. Assuming that the plan meets and serves a definite need in the community, the public relations program is one of education. Such a program is fundamentally one of interpreting the position of the voluntary hospital in the community. The public respects the hospital organization. Hospital activities can easily be dramatized. The public owns the hospital, the public supports the hospital, the public must accept the hospital service plan as an adjunct to the hospital.

When the community has recognized the plan as a hospital-sponsored project and when a substantial part of the community has enrolled in the plan, the public relations program is even more important. It continues to stimulate local pride in its success, to arouse confidence, to create public demand, to educate special groups, and is mindful of the opportunity of improved relations with the public, the medical profession, and the hospital personnel. The educational program is dignified, constructive' and purposeful. It reflects the character of its sponsors, the voluntary hospitals. At the same time, it carries no connotation of charity, but constantly reminds the public that, through this agency, they are themselves preparing for unpredictable hospital expense and that the means which they have chosen is self-sustaining. All 
agencies used in dignified promotional programs are enlisted in a public relations and educational program for hospital service plans.

\section{Enrollment Practice}

Membership in hospital service plans is usually available to employed people through their places of business on a group basis. A group is usually considered for membership regardless of size, if it is constituted of individuals working under the direction of a common employer. Usually the subscription rates are paid in full by the subscribers to the plan. In rare instances the employer pays the entire charges and only occasionally are payments made on a contributory basis with the employer carrying a partial responsibility for payment. Some plans do not permit employer contributions. Groups are formed by voluntary action on the part of employees. It is not reasonable to expect voluntary action from $100 \%$ of any class of employees on any proposition; therefore, minimum percentages of participation have been established by individual plans. In some localities, this minimum has been determined as $25 \%$ of the total number of employees in an organization. Recently one of the oldest and largest plans has set a minimum requirement of $75 \%$ participation before a group may be formed. Those in the employ of a company are not divided according to class rule, such as economic status or term of employment.

The employer's cooperation is necessary to present the program to his employees and to facilitate subscription payments by establishing a salary deduction procedure for this purpose. Plan directors, after experimentation, have concluded that payment through salary deduction is the most satisfactory method both from the point of view of the subscriber and of the plan management. A procedure less satisfactory, but necessary for governmental groups, is one by which the subscribing group makes its payment to the association through an individual who acts as treasurer for the group. It has been found least satisfactory to permit individuals to make payments directly to the association.

Before a group can be enrolled, the theory and practice of the hospital service plan must be explained in detail to the employer. If the proposal meets with his approval, a representative of the plan meets with the employees, preferably on company time, in a group meeting and explains the details of the service to them. The employees are given an opportunity to ask questions and to discuss the merits of the program. Literature describing the plan, and application blanks, are distributed. Employees are instructed to consider the proposition carefully and to return signed application blanks to a designated person on or before a closing date which has previously been established. During the interval between the first presentation of the plan and the closing date, additional literature, placards describing the plan and sometimes conferences with individuals are made available to describe the service more adequately to those who wish further clarification. On the closing date, the application cards are collected, tabulated, and either accepted or rejected, depending upon whether or not they meet the requirements for the organization of a group. 
Group enrollment is necessary because no medical examination is required before the applicant is accepted to participate. It is expected that a certain percentage of individuals in need of immediate hospital care. will enroll with the initial group. However, because of the group requirements, the strong support the weak. The size of the group does not seem particularly important in its relation to utilization of hospital service. Very small groups can be enrolled safely at slightly higher percentages of participation if the individuals are sold plan membership rather than permitted to buy it. A requirement for high percentage of participation eliminates self-selection against the hospital service plan because it minimizes the likelihood that employees, conscious of good health, will elect to withhold their membership to the material detriment of their fellow employees.

In a few instances, social groups have been permitted to organize for purposes of membership in a hospital service plan, and employee associations, labor unions, lodges, and church groups have been enrolled in several plans. They do not represent the same type of selection as the enrollment of employed people through places of business. Acceptance of this type of group is not general. They are enrolled subject to the judgment of individual plan directors. It has been determined that groups of individuals who have associated themselves solely for the purpose of meeting group requirements for membership in a hospital service plan do not represent a cross section of the population and ultimately use an excessive amount of hospital care.

Several plans have attempted to enroll individuals. In some such plans, these individuals have paid a slightly higher subscription rate than that charged to employed persons enrolled through groups in places of business. In other plans the individually-enrolled person has been required to complete a detailed health questionnaire. Generally speaking, non-profit hospital service plans have discontinued the enrollment of subscribers on an individual basis. No formula has yet been devised which will guarantee utilization of hospital service by this group at a rate which is not in excess of that experienced with the general public. If the plans are attempting to provide complete coverage of employed workers, at a price which they can afford to pay, it seems to require a mass scheme applied in a mass way.

\section{Coverage for Family Members}

Hospital benefits provided to family members of subscribers have varied from those plans in which only the employed person is permitted to enroll with no opportunity to protect dependent family members to those plans in which family members are entitled to the same benefits as those which are specified for the employed subscriber.

A number of plans do not provide the same type of benefit for the family participants as they do for the employed individual. These plans have been classified as "partial coverage plans." Partial coverage is a relative term in that it refers to coverage which is not provided in the same proportion to dependents as it is to the applicant subscriber. It has been provided in one or the other of the following two ways: Either the patient is entitled to a straight percentage reduction on the total 
cost of hospital benefits which are provided for the applicant subscriber or he is required to pay a flat per diem payment to the hospital during his stay for which he receives the same benefits as those specified for the subscriber.

There can be no question of the desirability of full family member coverage from the standpoint of the subscriber. The public is interested in protecting itself in full against the contingency of hospital care. Two aspects of the problem which have been considered before determining which program to adopt are: (I) Is full family member coverage financially sound? (2) Is the average wage of the employed person in localities where full family member coverage is to be offered, high enough to finance the additional subscription payment which is necessary to maintain economic soundness?

Although it is generally. felt that a full coverage program tends toward frivolous use of hospital services, in general it can be said that a liberalization of subscriber contracts apparently improves the selection among subscribers so that a disadvantage on one hand is probably offset by an advantage on the other. The general experience in the larger urban areas has been that plans without full family coverage have not been as acceptable as those which did not limit benefits for family members. Plans which have been organized during the past two years have without exception included some type of coverage for family members, the tendency being to initiate the plan with full family protection.

\section{Subscription Charges}

The subscription charges represent the source of income to the hospital service plan and must be adequate to pay for hospitalization of subscribers and administrative costs. Although it is generally assumed that the membership in a hospital service plan will represent a cross sectional average of the population, this is not always the case in a system where the membership is acquired on a voluntary basis. Therefore, the subscription rate is weighted to meet this variable.

The amount of hospital service used in any section of the country will not necessarily be the same as the national average. For this reason morbidity statistics compiled in the area contemplating the initiation of the hospital service plan have been the basis for the determination of the expected utilization of hospital service by the subscribing population. When the amount of hospitalization which the plan expects to provide to subscribers has been determined in terms of days, the cost of this service has been calculated on the basis of hospital costs in the communities to be served. To this figure is added the estimated cost of administering the plan and an amount to be set aside in a reserve account to be used at a later time in cases of emergency.

Obviously, the scope of benefits determine the cost of hospital service. Therefore, rates in various communities are influenced by this consideration.

It has been found that unemployed people use more hospital service than employed subscribers, that employed females use approximately $50 \%$ more hospital service than employed males, that unemployed females use about twice as much hos- 
pital care as employed males, and that dependent children use approximately twothirds the number of hospital days per year as employed males. Therefore, the selection of subscribers, more than any other single factor, affects the amount of hospital care which the plan expects to provide. If the plan enrolls subscribers only through their places of business, and accepts family members on a full coverage basis, it has been established that one day of hospital care per person, or three days of hospital care per family unit is a conservative estimate of utilization.

A hospital service plan expects to use no more than $20 \%$ of its earned income for the administration of the plan and ultimately this cost should be reduced to the neighborhood of $10 \%$ as the plan progresses in age and size. It has been recommended that from five to ten percent of earned income is adequate for contingency reserves. If these percentages are applied to an expected average per diem hospital cost of $\$ 6$, annual premiums of $\$ 7.50$ for an employed person, $\$ 15$ for a husband and wife contract, and $\$ 22.50$ for a family contract are adequate to meet anticipated liabilities.

In some communities, the rate for the applicant subscriber has been determined and each family member listed for coverage has been charged an additional amount equal to that paid by the' applicant subscriber. This arrangement has not proven particularly acceptable to the public and has led to adverse selection of risks which has militated against the plan. One of the first plans to initiate a hospital service program was set up on a two-rate basis, i.e., one rate for the single individual and another rate for the family group, regardless of whether that family included only husband and wife, or husband, wife and children. The family rate was established approximately midway between the theoretical charges which were calculated for husband and wife and family contracts.

The common practice has been to charge a proportionately high individual subscriber rate and a decreased family rate, because it is obviously more difficult for a person with a family to pay a higher rate for family protection than it is for a single individual to provide for his own protection. This arrangement seems the most satisfactory both from the standpoint of the public and the service plan. With a rate structure built on this basis, it is not necessarily true that all contracts in all classificaions are self-sustaining. The large family group is expected to use more hospital care than the small family unit, and ultimately to produce a deficit account for this classification. Conversely, the small family units develop a surplus account. Inasmuch as a head of a large family is less able to provide adequate hospitalization for his family members and because the object of hospital service plans is to provide the general public with more adequate hospital care, the establishment of a single rate for family members probably serves the more useful social purpose.

\section{Special Problems}

Reciprocity of Benefits: Several plans have developed reciprocal arrangements whereby a subscriber to one plan may use a member hospital in another plan and receive the full benefits of his "service" contract. However, subscribers to most plans 
who find it necessary to use non-member hospitals in cases of accident or emergency are provided cash per diem allowances. Often this fixed amount does not adequately meet the costs of the emergency hospitalization. Although complete and general reciprocity of benefits is desirable, probably it will be some time before such an agreement will be in active operation since each plan is slightly different in character and benefits.

Preferential Rates: Up to the present time, hospital service plans have based their rate structures upon the anticipated utilization of hospital service for the community as a whole. From time to time certain large employee organizations representing "selected risk" groups have suggested participation in plans on a cost-plus basis. The plans have felt that if their project is one community-wide in nature, no special consideration could be given to units making up the community. As a result several large organizations have declined to participate in the community program and have established hospital benefits as a part of an employees' benefit society or as a special project administered in conjunction with credit unions.

Definition of Hospital Service: Certain groups within the medical profession have objected to the provision of medical services incident to hospitalization which are provided to hospitalized bed patients by hospital employees. These include such services as physiotherapy, $\mathrm{X}$-ray, laboratory procedures and anesthesia which in most hospitals are charged to the patient as a part of his regular hospital bill.

It has not been the intention nor the performance of plan directors to practice medicine or to administer hospitals. They have devised a means by which the burden of hospital expense can be lifted from the individual, and it is their desire to include as benefits all items of hospital expense which, prior to the organization of the plan, were recognized as a part of hospital service and charged as such to hospitalized patients. If it is not objectionable for the hospital to bill the patient directly for such service, it is not logical to object to the means employed by the patient in making his remittance.

The ultimate decision as to what constitutes hospital and medical service usually rests with the definitions of such which are found in the medical practice acts of the various states.

\section{Growth and Expansion}

The membership in approved hospital service plans has progressed rapidly. The enrollment on January I, I933, was 200,000; on January I, I938, I,500,000; on July I, I939, 4,000,000; and enrollment on January I, I940, will probably exceed 5,000,000 'participants. Through their growth, the plans have demonstrated the demand for security against the unpredictable expense of health service.

Hospital service plans provide for the contingency of only one form of health service. The purchase of medical service on a similar basis would be desirable and undoubtedly acceptäble to the public. A joint hospital and medical program, through the agency of voluntary prepayment plans, could more adequately serve the health needs of the people. 
Particular emphasis is being placed upon the adaptation of these plans to the needs of the low income workers. Such a consideration raises special problems. It appears necessary that there be an integration of the public agencies for the support of plans which serve this class of employee. It may be necessary and desirable for hospitals to subsidize ward plans for patients who, without participation, would otherwise receive charity care. Ward plans must include a provision for medical service to serve the needs of this group adequately.

With the solution of these problems, voluntary plans will be better able to serve a greater number of people; they will have adjusted themselves to the needs of the public; and they will not ultimately emerge from their metamorphic development as a legislated creation with the attendant influences of political control. 